\title{
PERFORMANCE ENHANCEMENT OF TWO PHASE THERMOSYPHON FLAT-PLATE SOLAR COLLECTORS BY USING SURFACTANT AND NANOFLUID
}

\author{
Sandesh S. Chougule ${ }^{\mathrm{a}, *}$, Santosh Kumar Sahu ${ }^{\mathrm{a}}$, Ashok T. Pise ${ }^{\mathrm{b}}$ \\ ${ }^{a}$ Indian Institute of Technology, Indore, M.P., 453446, India \\ ${ }^{b}$ Government College of Engineering, Karad, M.S., 415124, India
}

\begin{abstract}
In this study the thermal performance of three different wickless heat pipe solar collectors were investigated by using pure water, watersurfactant and CNT-water nanofluid for different coolant mass flow rates and tilt angles $\left(20^{\circ}, 31.5^{\circ}, 40^{\circ}, 50^{\circ}\right.$ and $\left.60^{\circ}\right)$. First collector uses only pure water, the second one utilizes CNT nanoparticle of diameter 10-12 nm and 0.1-10 $\mu \mathrm{m}$ length with water as a base fluid. While the third collector uses water with $150 \mathrm{ppm}$ 2-ethyl-hexanol as coolant for the investigation. Experiments were carried out for the three collectors under the same experimental conditions. It is observed that the performance of the solar collector that uses 2-ethyl-hexanol surfactant with water as coolant is better compared to solar collectors that utilize pure water and CNT/water nanofluid.

Keywords: Wickless Heat Pipe, Nanofluid, Flat Plate collector, Heat Transfer, Surfactant
\end{abstract}

\section{INTRODUCTION}

In a conventional solar collector, tubes containing water as working fluid are attached to the absorber plate. The solar energy is absorbed by the working fluid and transferred to the storage tank either by natural or forced circulation. The drawbacks associated with conventional solar collectors include the pump and its power requirement, more space to obtain the natural circulation of working fluid, night cooling due to reverse flow of cooled water, pipe corrosion and limited heat carrying capacity of working fluid. Heat pipes are found to provide an alternative solution to the above problems.

Heat pipes, contain small amount of vaporizable fluid, transfers heat by evaporating the working fluid in a heating zone and condensing vapor in the cooling zone. Subsequently, the return flow of condensate to the heating zone occurs through the capillary structure which lies in the inner wall of the heat pipe. However, in certain applications, the return flow of the condensate to the heating zone occurs due to the gravity force and termed as gravity assisted heat pipes, wickless heat pipes or thermosyphon. Because of its ability to transfer large quantity of heat energy, the heat pipes has been widely used in several industrial applications, namely boilers, air-conditioning system, heat exchangers and solar water heating system. The wickless heat pipes are usually integrated with flat absorber plate of the solar heating system, to enhance the thermal performance. Numerous studies have been carried out to understand the thermal performance of two phase thermosyphon used in solar water heaters. Mathioulakis and Belessiotis (2002) reported the results obtained through both theoretical simulation and experimental investigation of a solar collector with heat pipes. They have used ethanol as working fluid and obtained the maximum instantaneous efficiency up to $60 \%$.
The thermal performance of a two-phase thermosyphon solar collector with various refrigerants was reported by Esen and Esen (2005). The thermal performance of the heat pipe with R410A as working fluid was found to be better compared to other refrigerants. The maximum collection efficiencies of solar collector throughout the day were found to be $50.84 \%, 49.43 \%$ and $48.72 \%$ for R410A, R407C and R-134a, respectively. The thermal performance of solar collector by using various refrigerants such as: R-134a, R12, and ethanol was reported by Enaburekhan and Yakasai (2009). The heat pipe that utilizes R-134a as working fluid exhibits maximum collection efficiency compared to other working fluids. Since thermosyphon utilizes phase change of the working fluid to transfer heat, selection of a working fluid is essential to achieve the maximum heat transfer capacity. Initially, Choi (1995) had made an attempt to use nanofluid (nanofluid-suspension) in thermal engineering due to its anomalous heat transfer characteristics. The colloidal suspension of nanoparticles in the base fluid with uniform dispersion is termed as nanofluid. Because of its enhanced heat transfer characteristics, nanofluids have been used in thermosyphon to improve the thermal performance. In an experimental study, Liu et al. (2007) used $\mathrm{CuO}$ nanofluids in a closed two-phase thermosyphon to study the thermal performance. The maximum enhancement in heat transfer coefficient and critical heat flux was found to be $160 \%$ and $120 \%$, respectively at the optimal nanoparticle concentration of $1 \%$. Liu et al. (2010) carried out experiments to study the thermal performance of closed thermosyphon by using carbon nanotubes (CNT) suspensions as working fluid. The maximum enhancement in heat transfer rate was obtained at optimal nanoparticle mass concentration of $2 \%$. The thermal performance of the closed two-phase thermosyphon by using various nanofluids (titaniumethanol and titanium-water suspension) was reported by Naphon et al. (2008). The heat transfer enhancement of the thermosyphon with titanium-ethanol suspension was found to be $10.6 \%$ higher compared to 
the heat pipe with ethanol. The thermal performance of the heat pipe with titanium-R11 suspension as working fluid was reported by Naphon et al. (2009). The efficiency of the heat pipe, with optimal nanoparticle mass concentration (0.1\%), found to be 1.4 times higher compared to that with the pure refrigerant. Gabriela et al. (2011) reported the comparison of thermal performance by using different working fluids, namely iron oxide-water suspension and deionized water. For 5.3\% (by volume) of iron oxide nanoparticle, the heat transfer performance was found to be better compared to the DI water. Liu et al. (2011) carried out experiments to study the thermal performance of open thermosyphon with $\mathrm{CuO}$ nanofluids in indoor environment. The $\mathrm{CuO}$ nanofluid at $1.2 \%$ mass concentration exhibits maximum enhancement in heat transfer rate compared to the deionized water. Chougule and Pise (2012) reported that CNT/water nanofluid posses excellent heat transfer characteristics and can be used in wickless solar heat pipe collector. The effect of solar tracking system on the performance of solar heat pipe collector was studied through experimental investigation (Chougule and Pise, 2011; Chougule et al., 2012). It is evident from the literature that only a few studies (Yuan et al., 2001 and Cheng et al., 2013) has been reported that utilize the water with surfactant as working fluid in the heat pipe solar collector. In view of this, an attempt has been made to study the thermal performance of heat pipe solar collector using 2-ehyl-hexanol surfactant with water as working fluid. The performance of heat pipe with CNT/water nanofluid as working fluid has also been studied in the present investigation. The comparison of thermal performance for nanofluid (CNT/water) and surfactant with water has been made for the given operating condition.

\section{EXPERIMENTAL METHOD}

\subsection{Experimental Set-up}

Figure 1 shows the schematic of the solar collector with wickless heat pipes. In this study, attempt has been made to evaluate the performance of two phase thermosyphon solar collector using water, CNT/water nanofluid and water/2-ethyl-hexanol surfactant. In view of this, three same size identical collectors have been fabricated for the investigation. Each collector consists of three absorber plate and each absorber plate contains one heat pipe filled with working fluid. The design parameters of various components heat pipe flat plate collectors are summarized in Table 1. Wickless heat pipes were made of copper tubes with an outer diameter of $12 \mathrm{~mm}$ and length of $625 \mathrm{~mm}$. The thickness, width and length of each copper absorber plate are $1 \mathrm{~mm}, 100 \mathrm{~mm}$, and $510 \mathrm{~mm}$, respectively. In order to enhance the ability to absorb the solar radiation, the absorber plates were painted dull black in the present investigation. Each individual wickless heat pipe was brazed to the absorber plate at $120 \mathrm{~mm}$ pitch. The heat exchanger, exchanges heat energy from heat pipe to coolant, consists of three interconnected steel collars with an OD of $40 \mathrm{~mm}$, ID of $36 \mathrm{~mm}$ and $90 \mathrm{~mm}$ long attached around the condensing section of the heat pipes. The three absorber plates with heat pipes and heat exchanger were housed in a collector case of $630 \mathrm{~mm}$ length and $360 \mathrm{~mm}$ breadth and $100 \mathrm{~mm}$ thickness. Thick insulation glass wool behind the absorber plate was used in order to avoid any loss of energy to the surroundings. Transparent glass was used as the upper glazing for the collector.

\subsection{Experimental Procedure}

In the present study PT100 thermo sensors, pyranometer, ambient air sensor and flow meter was used to measure inlet and outlet coolant temperature, solar irradiation ambient temperature and coolant flow rate, respectively. The mass flow rate of cooling water was measured by using a rotameter with an accuracy of $\pm 0.1 \mathrm{l} / \mathrm{min}$. The quantity of cooling water through the heat exchanger of each collector was adjusted by using flow control valve and measured by using a stop watch with $\pm 0.01 \mathrm{~s}$ accuracy and by using a graduated glass bottle of tolerance \pm 1 $\mathrm{cm}^{3}$. The temperatures of cooling water, plate and ambient air were measured by using PT100 thermo sensors with an accuracy of $\pm 0.10{ }^{\circ} \mathrm{C}$.
Data logger was used to measure the temperatures. The instantaneous value of global solar radiation intensity was measured by the pyranometer (Model-DWR 8101, Make-DynaLab).

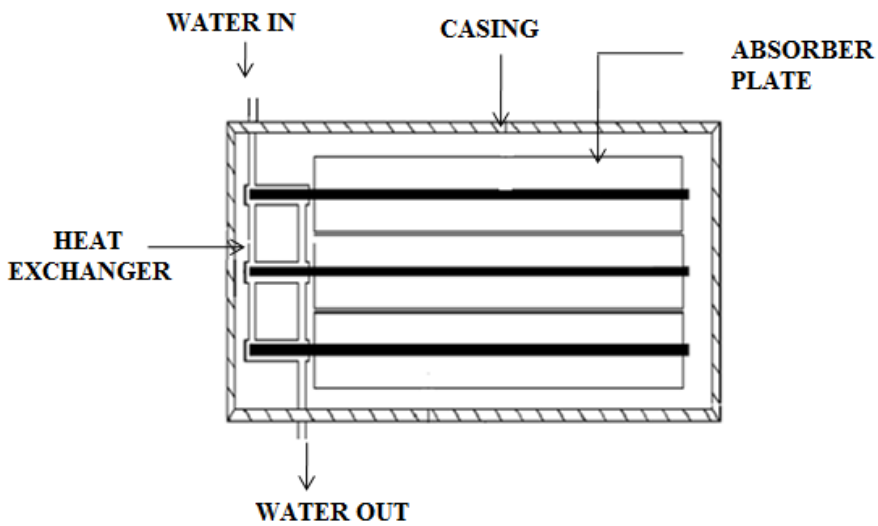

Fig. 1 Schematic of thermosyphon solar collector

The solar collector was installed on a tiltable stand facing south and tested under outdoor conditions of Kolhapur, India (latitude $16.69^{0} \mathrm{~N}$; longitude $74.22^{0} \mathrm{E}$ ). Experiments were carried out throughout the day from 10:00 a.m. to 4:00 p.m. and values were recorded at each half hour interval. During each test run the solar radiation intensity $\left(\mathrm{I}_{\mathrm{t}}\right)$, ambient air temperature $\left(T_{a}\right)$, inlet cooling water temperature $\left(T_{i}\right)$ and outlet cooling water temperature $\left(T_{0}\right)$ of each collector were recorded for a fixed mass flow rate.

The experiments were carried into the two groups:

- Tests were carried out throughout the day for various tilt angles, namely, $20^{\circ}, 31.5^{\circ}, 40^{\circ}, 50^{\circ}$ and $60^{\circ}$ for a given mass flow rate $(0.00125 \mathrm{~kg} / \mathrm{sec})$.

- Tests were conducted for varied range of mass flow rates $(0.00125 \mathrm{~kg} / \mathrm{sec}$ and $0.0022 \mathrm{~kg} / \mathrm{sec})$ for a given tilt angle

Table 1 Specifications of the different components of the collectors.

Gross dimensions
Length $0.63 \mathrm{~m}$ Width $0.40 \mathrm{~m} \quad$ Depth $0.1 \mathrm{~m}$

Transparent cover

Material: white glass

Absorber plate

Material: copper Length $0.51 \mathrm{~m}$ Pitch distance $0.12 \mathrm{~m}$

Thickness $0.001 \mathrm{~m}$ Coating: black

Wickless heat pipes

Material: copper $\quad$ Outer diameter $0.012 \mathrm{~m}$

Inner diameter $0.010 \mathrm{~m} \quad$ Evaporator length $0.51 \mathrm{~m}$

Condenser length $0.085 \mathrm{~m}$ Adiabatic length $0.030 \mathrm{~m}$

Total length $0.625 \mathrm{~m}$

Number of Heat pipes in each collector 3

Working fluid: Collector No.1:- D.I. water

Collector No.2:-CNT-water Nanofluid $(\varphi=0.15 \%)$

Collector No.3:- water-surfactant

Insulation

Material: glass wool Thickness $0.05 \mathrm{~m}$ Position: Back and sides

Box material

Frame: aluminum Base: galvanized iron 
The rate of thermal energy input $\left(\mathrm{Q}_{\text {in }}\right)$, the rate of thermal energy gain $\left(Q_{g}\right)$ and the instantaneous efficiency $(\eta)$ of each collector were calculated as below,

$$
\begin{gathered}
Q_{\text {in }}=I_{t} A_{\text {coll }} \\
Q_{g}=\dot{m} C_{w}\left(T_{o}-T_{i}\right) \\
\eta=\frac{Q_{g}}{Q_{i n}}
\end{gathered}
$$

The energy gain $\left(Q_{g}\right)$ and the efficiency $(\eta)$ of the collector were calculated by using various the basic quantities such as: mass flow rate of coolant, temperature of inlet and outlet coolant and solar radiation intensity. Considering the errors of various basic quantities, the maximum uncertainty of the energy gain $\left(Q_{g}\right)$ and the efficiency $(\eta)$ of the collector were found to be less than $2.5 \%$ and $6 \%$, respectively.

\section{RESULT AND DISCUSSION}

Experiments were carried out to investigate the thermal performance of heat pipe solar collector by using various working fluids for heat pipes such as: pure water, water/2-ethyl-hexanol, CNT/water nanofluid. The results are depicted in Figs. 2-6. The variation of various parameters , namely, the rate of solar energy input, ambient air temperature, inlet cooling water temperature, outlet water temperature and plate temperature for three different wickless heat pipe flat plate solar collectors is shown in Figs. 2-3. It is observed that the solar intensity increases, reached maximum and then falls with time (Fig.2). Peak value of solar radiation intensity is found to be different for various tilt angles. The maximum value average solar intensity was observed at $31.5^{0}$.

\subsection{Effect of tilt angle}

Tests were performed for several tilt angles in three different solar heat pipe collectors under same climatic conditions. First collector uses pure water, second one utilizes CNT/water nanofluid and third collector uses 2-ethyl-hexanol surfactant with water as working fluid. The variation on instantaneous efficiency of three collectors for various tilt angles were shown in Figs. 4(a)-(e).

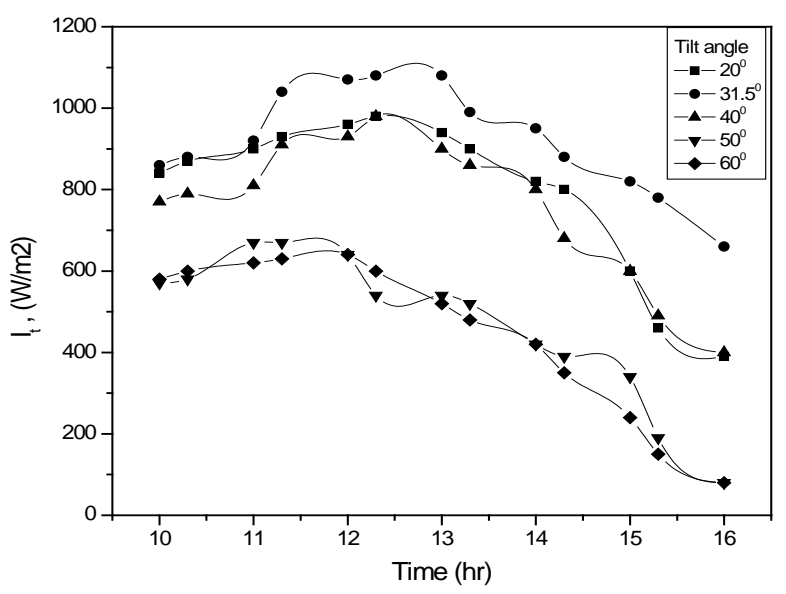

Fig. 2 Hourly variation of solar intensity for various tilt angles.

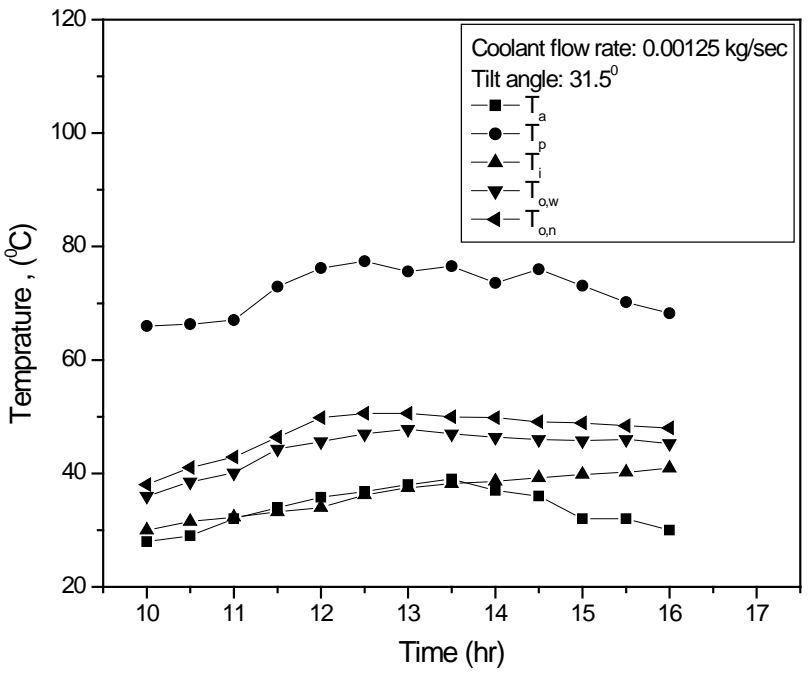

Fig. 3 Instantaneous variation of $T_{a}, T_{p}, T_{i}, T_{o, w}$, and $T_{o, n}$

The water and water/surfactant used collectors show enhancement in thermal performance with increase in tilt angle of collector. The average collector efficiency of water and water/surfactant used collectors are low at lower tilt angles and it increases with increase in the tilt angle up to $50^{\circ}$ angles then it decreases. The average collector efficiency that uses water working fluid is found to be $24 \%, 27 \%, 31 \%$, $43 \%$ and $35 \%$ at $20^{\circ}, 31.5^{\circ}, 40^{\circ}, 50^{\circ}$ and $60^{\circ}$ tilt angle, respectively. While, average collector efficiency that uses surfactant/water working fluid is found to be $35 \%, 38 \%, 43 \%, 54 \%$ and $49 \%$ at $20^{\circ}, 31.5^{\circ}, 40^{\circ}$, $50^{\circ}$ and $60^{\circ}$ tilt angles respectively. The average collector efficiencies recorded for CNT/water working fluid collector at $20^{\circ}, 31.5^{\circ}, 40^{\circ}, 50^{\circ}$ and $60^{\circ}$ tilt angles are $41 \%, 36 \%, 41 \%, 51 \%$ and $45 \%$. The average collector efficiency of the solar collector that uses CNT/water nanofluid decreases with the tilt angle ranging from $20^{\circ}-31.5^{\circ}$, increases with tilt angle varying from $31.5^{\circ}-50^{\circ}$ and found to decrease beyond $50^{\circ}$. Table 2 shows variation of average efficiency at various tilt angles with different working fluid for solar heat pipe collector. The thermal performance of solar heat collector with water/surfactant as working fluid for heat pipe is found better as compared to water and CNT/water nanofluid used solar heat pipe collector.

The percentage enhancement in thermal performance of $\mathrm{CNT} /$ water nanofluid working fluid collector as compared to water working fluid collector at $20^{\circ}, 31.5^{\circ}, 40^{\circ}, 50^{\circ}$ and $60^{\circ}$ tilt angle are $66 \%, 34 \%, 32 \%, 18 \%$ and $31 \%$. The percentage enhancement in thermal performance for water/surfactant working fluid collector as compared to water collector at $20^{\circ}, 31.5^{\circ}, 40^{\circ}, 50^{\circ}$ and $60^{\circ}$ tilt angle are $45 \%, 41 \%, 38 \%, 25 \%$, and $37 \%$. It shows that, percentage enhancement of water/surfactant based heat pipe collector is observed higher than CNT/water nanofluid used solar collector at angle $31.5^{\circ}$, $40^{\circ}, 50^{\circ}, 60^{\circ}$ when compared with water working fluid solar heat pipe collector. But at $20^{0}$ tilt angle CNT/water nanofluid used solar collector show higher thermal performance than water/surfactant based heat pipe collector at $20^{\circ}$, because of low entrainment limit in CNT-water heat pipes at low tilt angle. The percentage enhancement in CNT/water nanofluid collector at $20^{\circ}$ is found more than water/surfactant working fluid solar heat pipe collector when compared to water working fluid collector, because of at these tilt angle after vapor condensation in condenser section when condensed vapors are travelling back to evaporator section of heat pipe CNT working fluid offer lower resistance to condensed vapour in case of CNT nanofluid heat pipe collector. 


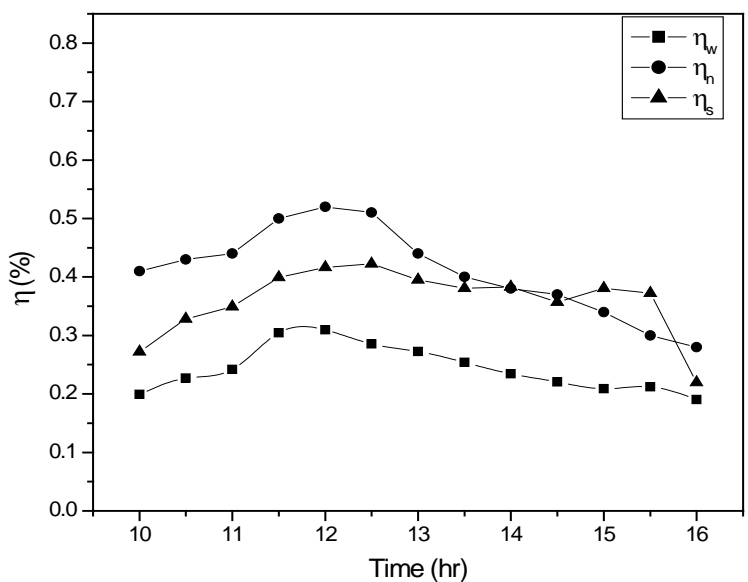

(a)

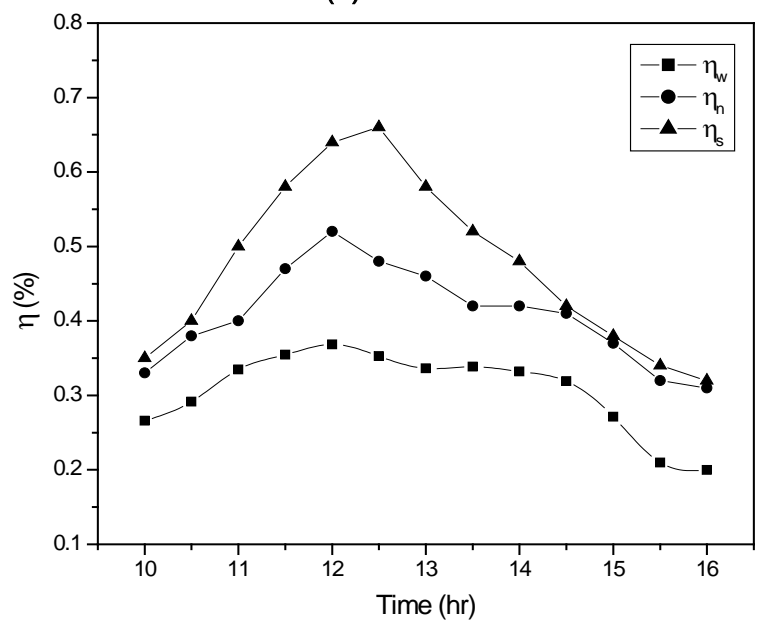

(c)

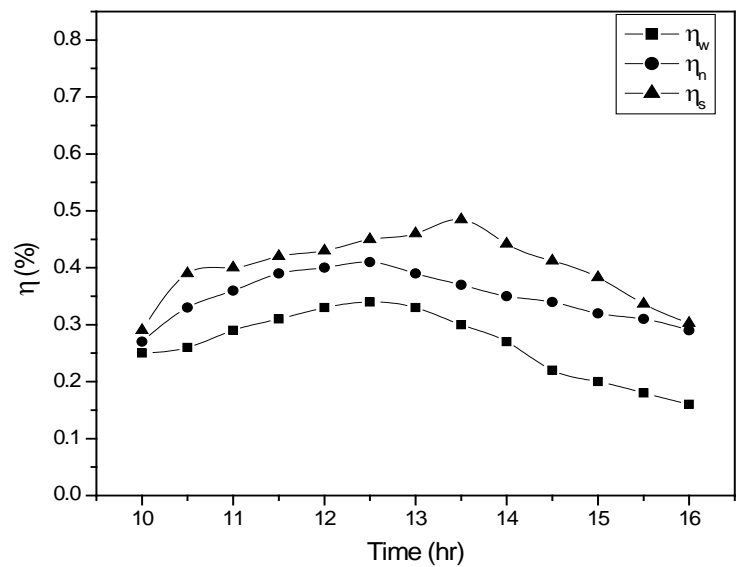

(b)

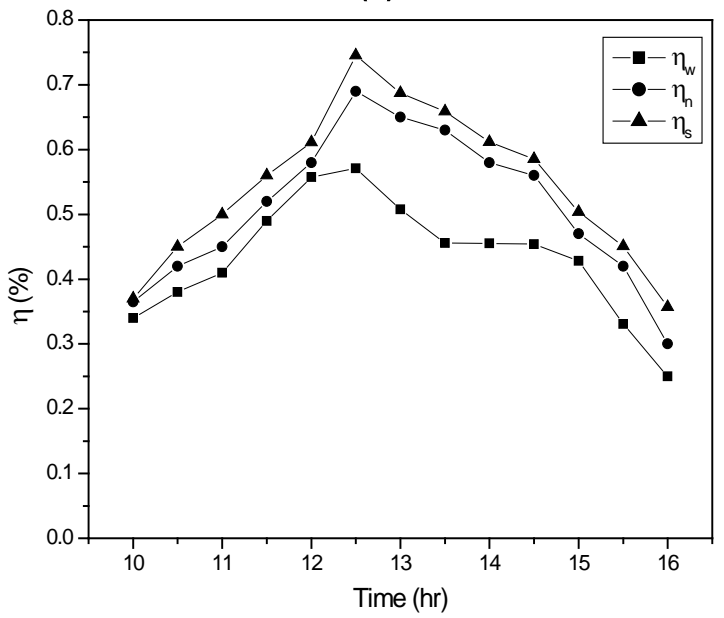

(d)

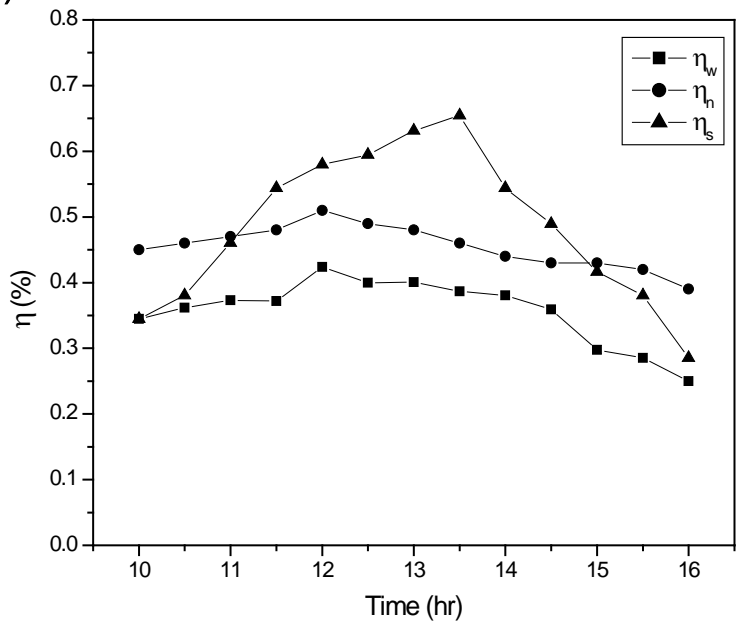

(e)

Fig. 4 Daily variation of instantaneous efficiency of different working fluids at (a) $\theta=20^{\circ}$, (b) $\theta=31.5^{\circ}$, (c) $\theta=40^{\circ}$, (d) $\theta=50^{\circ}$, (e) $\theta=60^{\circ}$.

For $50^{\circ}$ tilt angle, the water, CNT/water nanofluid and surfactant/water exhibit the maximum instantaneous efficiency. The maximum instantaneous efficiency of the collector for CNT/water nanofluid and surfactant/water was found to be $69 \%\left(\right.$ at $50^{\circ}$ ) and $75 \%($ at $50^{\circ}$ ), respectively.

\subsection{Effect of coolant rate}

The test data have been collected from several test runs under quasisteady state condition. The maximum variations in ambient, inlet and outlet temperature for this test period are found to be $0.5^{0} \mathrm{C}, 0.2^{0} \mathrm{C}$ and $0.4^{0} \mathrm{C}$, respectively.

Figures 5(a)-5(c) depict the variation of instantaneous efficiency of various solar heat pipe collectors throughout the day. These collectors use different working fluids such as: water, CNT/water nanofluid and surfactant/water. Tests were conducted with three different collectors for different flow rate, namely, $0.00125 \mathrm{~kg} / \mathrm{sec}$ and $0.0022 \mathrm{~kg} . \mathrm{sec}$ for a given tilt angle of $31.5^{0}$. It is observed that all collector exhibit better performance at higher coolant flow rate. This may be due to fact that, higher coolant flow rate of coolant enhances the condensation amount 
of vapors inside the heat pipe. This enhances the heat transfer rate for all collectors. With the use of water as working fluid, better performance was obtained because of condensation of more amount of vapour in the condensing section. For CNT/water nanofluid, the performance increases because of higher effective thermal conductivity of nanoparticles in the nanofluid. This enhances the vapour formation and condensation rate in the evaporator and condensing section, respectively.

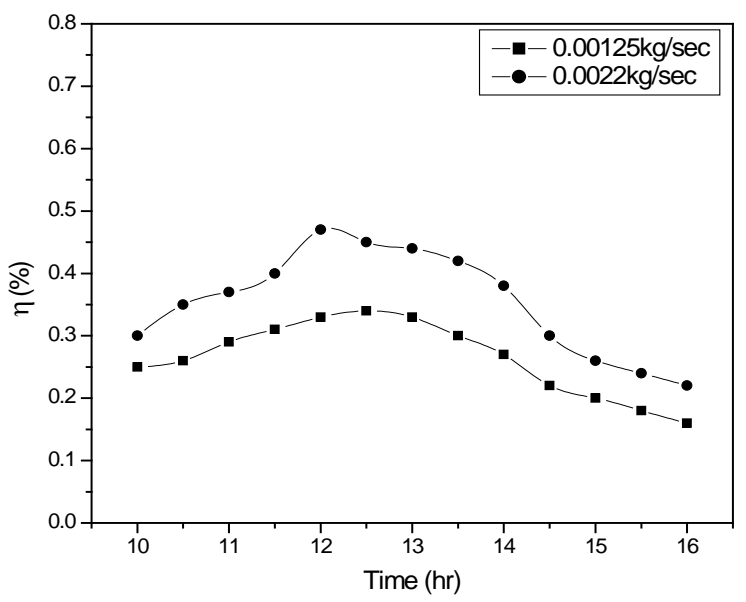

(a)

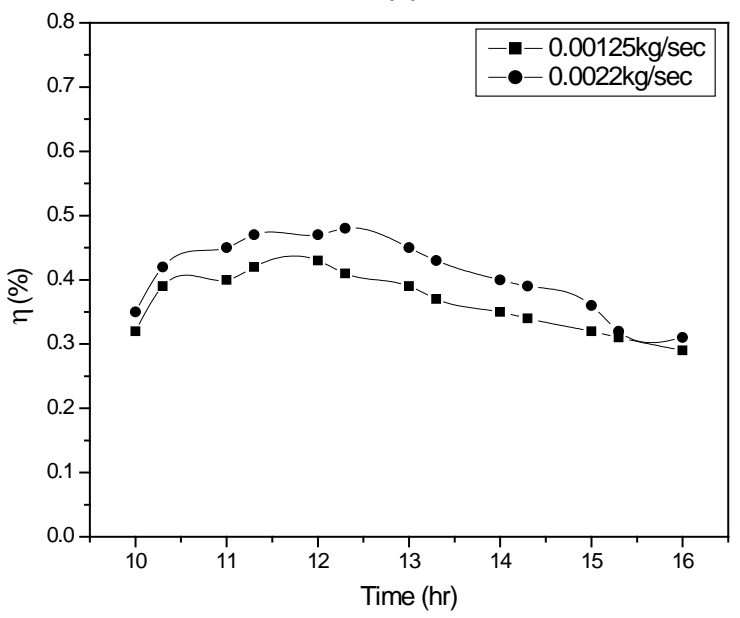

(b)

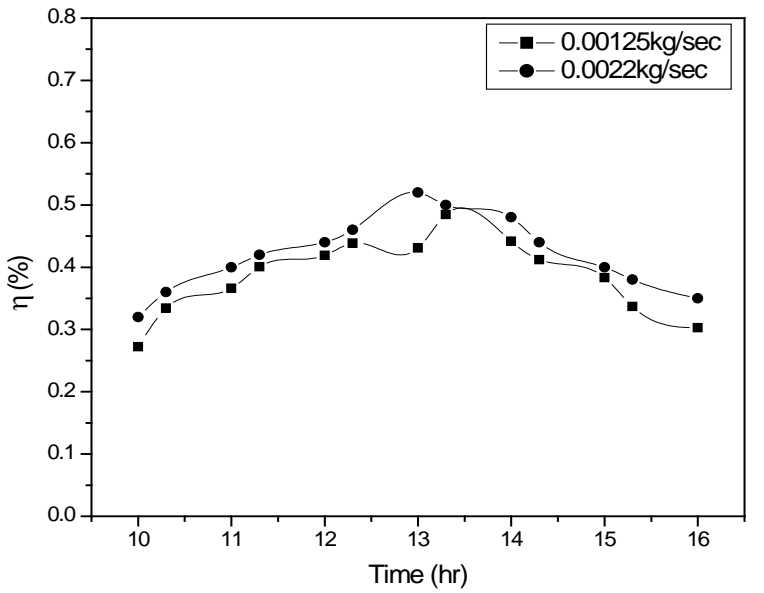

(c)

Fig. 5 Daily variation of instantaneous efficiency for different working fluid (a) water (b) CNT/water (c) water/2-etehyl-hexanol.

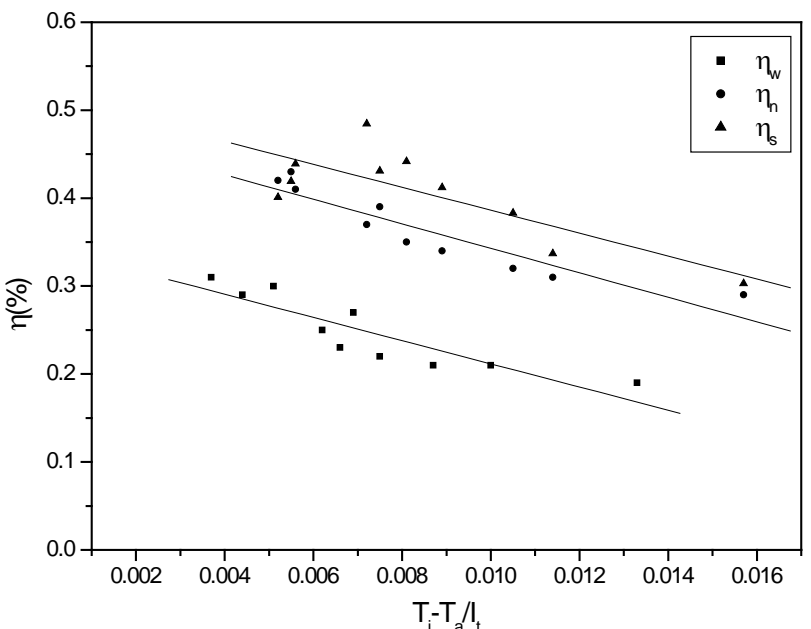

Fig. 6 Variation of collector efficiency with factor $\mathrm{T}_{\mathrm{i}}-\mathrm{T}_{\mathrm{a}} / \mathrm{I}$

Table 2 Average efficiencies (\%) at various tilt angle for various working fluid solar thermosyphon collector

\begin{tabular}{|c|c|c|c|}
\hline \multirow{2}{*}{ Tilt angle } & water & $\begin{array}{c}\text { CNT-water } \\
\text { nanofluid }\end{array}$ & $\begin{array}{c}\text { Water- } \\
\text { surfactant }\end{array}$ \\
\cline { 2 - 4 } & 24 & 41 & 35 \\
\hline $31.5^{0}$ & 27 & 36 & 38 \\
\hline $40^{0}$ & 31 & 41 & 43 \\
\hline $50^{0}$ & 43 & 51 & 54 \\
\hline $60^{\circ}$ & 35 & 45 & 49 \\
\hline
\end{tabular}

\subsection{Effect of Heat Loss Factor}

Figure 6 shows the variation of collector efficiency for various working fluids such as: pure water, CNT/water, water/surfactant in the heat pipe of the collector. The experiments were carried out for the given mass flow rate of $0.00125 \mathrm{~kg} / \mathrm{sec}$. It may be noted that by curve fitting technique, the collector efficiency with various working fluids (pure water, CNT/water, water/surfactant) can be expressed as a linear function of $\left(T_{i}-T_{a}\right) / I_{t}$. The intersection of the trend line with the vertical efficiency axis gives as absorbed energy parameter $\left(F_{R}(\tau \alpha)\right)$. At this point, the temperature of the inlet fluid to the collector equals to the ambient temperature and the collector efficiency is maximum. The slope of the trend line indicates the amount of energy removed from the solar collector and equals to $F_{R} U_{L}$. The intersection point of the trend line with the horizontal axis indicates the zero efficiency point and termed as stagnation point. This situation arises when no fluid flow occurs in the collector. The magnitude of heat removal factor $\left(F_{R} U_{L}\right)$ and heat absorption factor $\left(F_{R} U_{L}\right)$ for various working fluids are obtained in the present investigation and summarized in Table 3. It is observed that the collector that uses water/surfactant and working fluid exhibits highest $F_{R}(\tau \alpha)$ and lowest $F_{R} U_{L}$ among various fluids. This indicates that the thermal performance of solar collector with water/2ethyl-hexanol is higher followed by CNT/water nanofluid and water as a working fluid in the heat pipe.

Table $3 \quad F_{R}(\tau \alpha)$ and $F_{R} U_{L}$ values of wickless solar heat pipe collector at different working fluid

\begin{tabular}{|c|c|c|}
\hline Working fluid & $F_{R} U_{L}$ & $F_{R}(\tau \alpha)$ \\
\hline Pure water & 13.93 & 0.34 \\
\hline CNT/water nanofluid & 13.19 & 0.48 \\
\hline Water/surfactant & 13.03 & 0.50 \\
\hline
\end{tabular}




\section{CONCLUSIONS}

An experimental study has been carried out to investigate the thermal performance of heat pipe solar collector by using different working fluids for heat pipes such as: pure water, water/2-ethyl-hexanol, CNT/water nanofluid. Following conclusions are made from the experimental study and is detailed below:

- The thermal performance of solar heat pipe collector is higher by using water/2-ethyl-hexanol followed by CNT/water nanofluid, water as a working fluid for the heat pipe

- The heat transfer rate is found to increase by increasing the tilt angle from $20^{\circ}$ to $50^{\circ}$ for both cases, namely, pure water and water/2-ethyl-hexanol. While, the heat transfer rate decreases by increasing the tilt angle beyond $50^{\circ}$.

- The heat transfer performance of the solar collector that uses $\mathrm{CNT} /$ water nanofluid decreases with the tilt angle ranging from $20^{0}-31.5^{0}$, increases with tilt angle varying from $31.5^{\circ}-50^{\circ}$ and found to decrease beyond $50^{\circ}$.

- Solar heat pipe collector that uses nanofluid as working fluid provides better performance at higher tilt angles (at $50^{\circ}$ ). The collector will provide improvement in the thermal performance by locating solar heat pipe collector at the place where the angle of getting maximum total solar radiation matches with higher performance tilt angle of solar heat pipe collector.

\section{ACKNOWLEDGEMENTS}

The authors would like to thank Dr. S.H. Pawar Vice-Chancellor, D.Y.Patil University, Kolhapur for providing the facility to use Nanotechnology lab. Also thankful to V.S.Paralikar, Golden Star Technical Services Pvt. Ltd., Pune for providing help in manufacturing the heat pipes.

\section{NOMENCLATURE}

A collector effective area, $\mathrm{m}^{2}$

C specific heat, $\mathrm{J} / \mathrm{kgK}$

I total solar radiation intensity, $\mathrm{W} / \mathrm{m}^{2}$

${ }_{\mathrm{R}}$ heat removal factor

$\dot{m} \quad$ mass flow rate through heat exchanger, $\mathrm{kg} / \mathrm{sec}$.

$T$ temperature, ${ }^{0} \mathrm{C}$

$Q_{g} \quad$ rate of energy gain, W

$Q_{\text {in }}$ rate of energy input, W

$U_{L} \quad$ overall loss coefficient of solar collector $\left(\mathrm{W} / \mathrm{m}^{2} \mathrm{~K}\right)$

$\theta \quad$ tilt angle

$\eta \quad$ collector instantaneous efficiency ,dimensionless

$\tau \alpha \quad$ absorptance-transmittance product

\section{Subscripts}

a ambient

coll collector aperture

i inside

n nanofluid

o outside

t total

p plate

w water

s surfactant

\section{REFERENCES}

Choi, S.U.S., 1995, "Enhancing Thermal Conductivity of Fluids with Nanoparticles, Developments and Applications of Non-Newtonian Flows,” FED-231/MD-66, 99-105.
Cheng, W., Xie, B., Han, F., Chen, H., 2013, “An Experimental Investigation of Heat Transfer Enhancement by Addition of HighAlcohol Surfactant (HAS) and Dissolving Salt Additive (DSA) In Spray Cooling,” Experimental Thermal and Fluid Science, 45, 198-202. http://dx.doi.org/10.1016/j.expthermflusci.2012.11.005

Chougule, S. S., and Pise, A.T., 2012, "Studies of CNT Nanofluid in Two Phase system," International Journal of Global Technology Initiatives, 1, F14-F20.

Chougule, S. S., and Pise, A.T., 2011, "Experimental Investigation Heat Transfer Augmentation of Solar Heat Pipe Collector by Using Nanofluid," 21st National and 10TH ISHMT-ASME Heat and Mass Transfer Conference, Madras, India.

Chougule, S.S., Pise, A.T. and Madane P.A., 2012, "Performance of Nanofluid-Charged Solar Water Heater by Solar Tracking System," Proc. of the IEEE-ICAESM 2012 Nagapattiam, India, VI, 247-254.

Esen, M. and Esen, H., 2005, "Experimental Investigation of A TwoPhase Closed Thermosyphon Solar Water Heater," International Journal of Solar Energy, 79, 459-468.

http://dx.doi.org/10.1016/j.solener.2005.01.001

Enaburekhan, J., Yakasai, U., 2009, "Performance Evaluation of A Refrigerant-Charged Integrated Solar Water Heater in Northern Nigeria," Desalination, 243, 208-217.

http://dx.doi.org/10.1016/j.desal.2008.05.014

Gabriela, H., Angel, H., Ion, M., Florian, D., 2011, "Experimental Study of The Thermal Performance of Thermosyphon Heat Pipe Using Iron Oxide Nanoparticles”, International Journal of Heat and Mass Transfer, 54, 656-661.

http://dx.doi.org/10.1016/j.ijheatmasstransfer.2010.09.005

Lin, Lu, Zhen-Hua, Liu, Hong-Sheng, Xiao, 2011, “Thermal Performance of an Open Thermosyphon Using Nanofluids for HighTemprature Evacuated Tubular Solar Collectors Part 1: Indoor Experiments”, Solar energy, 85, pp. 379-387. http://dx.doi.org/10.1016/j.solener.2010.11.008

Liu, Z.H., Yang, X.F., Wang, G.S., Guo, G.L., 2007, "Effect of Nanoparticles in Nanofluid on Thermal Performance in A Miniature Thermosyphon,” J. Appl. Phys., 102, 013526.

http://link.aip.org/link/doi/10.1063/1.2748348

Liu, Z.H., Yang, X.F., Wang, G.S., Guo, G.L., 2010, "Influence of Carbon Nanotube Suspension on the Thermal Performance of a Miniature Thermosyphon," International Journal of Heat Mass Transfer, 53, 1914-1920.

http://dx.doi.org/10.1016/j.ijheatmasstransfer.2009.12.065

Mathioulakis, E., Belessiotis, V., 2002, “A New Heat-Pipe Type Solar Domestic Hot Water System,” International Journal of Solar Energy, 72, 13-20.

http://dx.doi.org/10.1016/S0038-092X(01)00088-3

Naphon, P., Assadamongkol, P., Borirak, T., 2008, “Experimental Investigation of Titanium Nanofluids on the Heat Pipe Thermal Efficiency,” Int. Commun. Heat Mass Transfer, 35, 1316-1319. http://dx.doi.org/10.1016/j.icheatmasstransfer.2008.07.010

Naphon, P., Thongkum, D., Assadamongkol, P., 2009, "Heat Pipe Efficiency Enhancement with Refrigerant-Nanoparticles Mixtures," International Journal of Energy Conversion Management, 50, 772-776. http://dx.doi.org/10.1016/j.enconman.2008.09.045

Z., Yuan, K.E., Herold, 2001, "Surface Tension of Pure Water and Aqueous Lithium Bromide With 2-Ethyl-Hexanol," International Journal of Applied thermal Engineering, 21, 881-897.

http://dx.doi.org/10.1016/S1359-4311(00)00088-0 